\title{
2-Phenylethyl Isothiocyanate Exerts Antifungal Activity against Alternaria alternata by Affecting Membrane Integrity and Mycotoxin Production
}

\author{
Miao Zhang, Yongcai Li *, Yang Bi, Tiaolan Wang, Yupeng Dong, Qian Yang and Tingting Zhang \\ College of Food Science and Engineering, Gansu Agricultural University, Lanzhou 730070, China; \\ Zhangmiao321@hotmail.com (M.Z.); biyang@gsau.edu.cn (Y.B.); wangtiaolan@hotmail.com (T.W.); \\ Dong19940123@outlook.com (Y.D.); yangq@st.gsau.edu.cn (Q.Y.); Ztting321@hotmail.com (T.Z.) \\ * Correspondence: lyc@gsau.edu.cn; Tel.: +86-931-763-1694; Fax: +86-931-763-1201
}

Received: 2 February 2020; Accepted: 13 February 2020; Published: 15 February 2020

check for updates

\begin{abstract}
Black spot caused by Alternaria alternata is one of the important diseases of pear fruit during storage. Isothiocyanates are known as being strong antifungal compounds in vitro against different fungi. The aim of this study was to assess the antifungal effects of the volatile compound 2-phenylethyl isothiocyanate (2-PEITC) against $A$. alternata in vitro and in pear fruit, and to explore the underlying inhibitory mechanisms. The in vitro results showed that 2-PEITC significantly inhibited spore germination and mycelial growth of A. alternata-the inhibitory effects showed a dose-dependent pattern and the minimum inhibitory concentration (MIC) was $1.22 \mathrm{mM}$. The development of black spot rot on the pear fruit inoculated with A. alternata was also significantly decreased by 2-PEITC fumigation. At $1.22 \mathrm{mM}$ concentration, the lesion diameter was only $39 \%$ of that in the control fruit at 7 days after inoculation. Further results of the leakage of electrolyte, increase of intracellular $\mathrm{OD}_{260}$, and propidium iodide (PI) staining proved that 2-PEITC broke cell membrane permeability of A. alternata. Moreover, 2-PEITC treatment significantly decreased alternariol (AOH), alternariolmonomethyl ether (AME), altenuene (ALT), and tentoxin (TEN) contents of A. alternata. Taken together, these data suggest that the mechanisms underlying the antifungal effect of 2-PEITC against $A$. alternata might be via reduction in toxin content and breakdown of cell membrane integrity.
\end{abstract}

Keywords: 2-phenylethyl isothiocyanate; Alternaria alternata; pear fruit; black spot; membrane integrity; mycotoxin

Key Contribution: 2-PEITC exhibited/demonstrated antifungal effects on A. alternata in vitro and in pear fruit and inhibited spore germination and mycelial growth of $A$. alternata. 2-PEITC was shown to damage cell membrane integrity of A. alternate, decreasing mycotoxin production by A. alternata. 2-PEITC significantly decreased black spot rot of harvested pear fruits.

\section{Introduction}

Alternaria alternata is a filamentous fungus [1] that causes different diseases during the postharvest shelf-life of horticultural products including black rot of cherry tomato [2], moldy core and core rot of apple [3], Alternaria brown spot of citrus [4], black rot of Hylocereus undatus [5], and Alternaria rot of netted melon [6]. A. alternata, the causal agent of black spot in pear, initially infects the fruit via styles or peel during the growing season and remains latent until fruit maturity [7], which results in severe economic and industrial losses [8]. Most Alternaria species produce mycotoxins during growth that pose potential threat to animal and human health [9]. These mycotoxins belong to three classes including dibenzo- $\alpha$-pyrone derivatives (alternariol, AOH; alternariol monomethyl ether, AME; and alteuene, ALT), tetramic acid derivatives (tenuazonic acid, TeA), and perylene derivatives (altertoxin I, ATX-I; 
and the related compounds altertoxins II and III) [10,11]. Therefore, inhibiting mycotoxin synthesis or reducing mycotoxin levels are main fields of research interest in controlling postharvest black spot disease in fruit and vegetables. Recently, chemical fungicides (orthophenylphenate and imazalil) were found to be effective in controlling A. alternata [12]; however, the continued use of these fungicides has led to the emergence of resistant strains and has generated environmental pollution and food security issues $[13,14]$. Therefore, it is necessary to find safe and effective natural alternatives to chemical fungicides to control postharvest diseases of pear fruit.

Vegetables of the genus Brassica such as cauliflower, broccoli, cabbage, canola, kale, turnip, radish, and various mustards produce a good deal of potentially antimicrobial compounds called glucosinolates (GSLs) $[15,16]$. Isothiocyanates are one of the products of GSL hydrolysis by the enzyme myrosinase (thioglucosidase) [17]. They mainly include phenethyl isothiocyanate (PEITC), allyl isothiocyanate (AITC), benzyl isothiocyanate (BITC), erucin (ERU), phenylhexyl isothiocyanate (PHI), and sulforaphane (SFN) [18]. Studies have shown that these isothiocyanates reduce the risk of some types of cancer [19,20] and cardiovascular diseases [21]. Furthermore, isothiocyanates have demonstrated potential inhibitory activity against fungi [22], nematodes [23,24], bacteria [25,26], insects [27], and weeds [28]. Isothiocyanates have been reported to possess fungistatic and fungitoxic activities against a variety of plant pathogens [29]. Studies have demonstrated fungicidal activity for various compounds as follows: AITC against Monilinia laxa of nectarine and peach [30], Botrytis cinerea of strawberry [31], and Aspergillus parasiticus of pizza crust [32]; BITC against Aspergillus ochraceus of peanuts, green coffee, grapes, and soybeans [33], Phymatotrichopsis omnivora of cotton [34], and A. alternata of tomato [35]; and 2-propenyl-isothiocyanate against Penicillium expansum of pears [36]. However, the inhibitory effect depends on the type and concentration of isothiocyanate, the type of fungus, application method, and time of exposure. Among them, 2-phenylethyl isothiocyanate (2-PEITC), a major isothiocyanate, is the most common glucosinolate in Brassica species. Studies have shown that the antimicrobial activity of 2-PEITC against soil microorganisms [37], plant pathogenic bacteria [38], and clinical isolates. However, the role of 2-PEITC on fungal pathogens in postharvest fruit and its mode of action are largely unknown. The aim of the present study was to evaluate the inhibitory effects of 2-PEITC on A. alternata both in vitro and in pear fruit, as well as to further ascertain the antifungal mechanisms of 2-PEITC by analyzing membrane integrity and toxin production.

\section{Results}

\subsection{Effects of 2-PEITC on Spore Germination and Mycelial Growth of A. alternata}

The spore germination rate of $A$. alternata was significantly inhibited after 2-PEITC fumigation, and a positive correlation $\left(R^{2}=0.8979, p<0.05\right)$ was observed between the concentration of 2-PEITC and the inhibitory effect (Figure 1A). 2-PEITC at $0.305 \mathrm{mM}$ inhibited spore germination of $A$. alternata after incubation for $2 \mathrm{~h}$. At $4.88 \mathrm{mM}$, the rate of spore germination was inhibited by $81 \%$ after $8 \mathrm{~h}$ of incubation.

2-PEITC effectively inhibited the mycelial growth of $A$. alternata, and the inhibitory effect showed a dose-dependent manner (Figure 1B,C); 2-PEITC at $1.22 \mathrm{mM}$ or higher concentrations entirely inhibited the mycelial growth of $A$. alternata 2 days after treatment. Thus, the minimum inhibitory concentration (MIC) of 2-PEITC was $1.22 \mathrm{mM}$. 

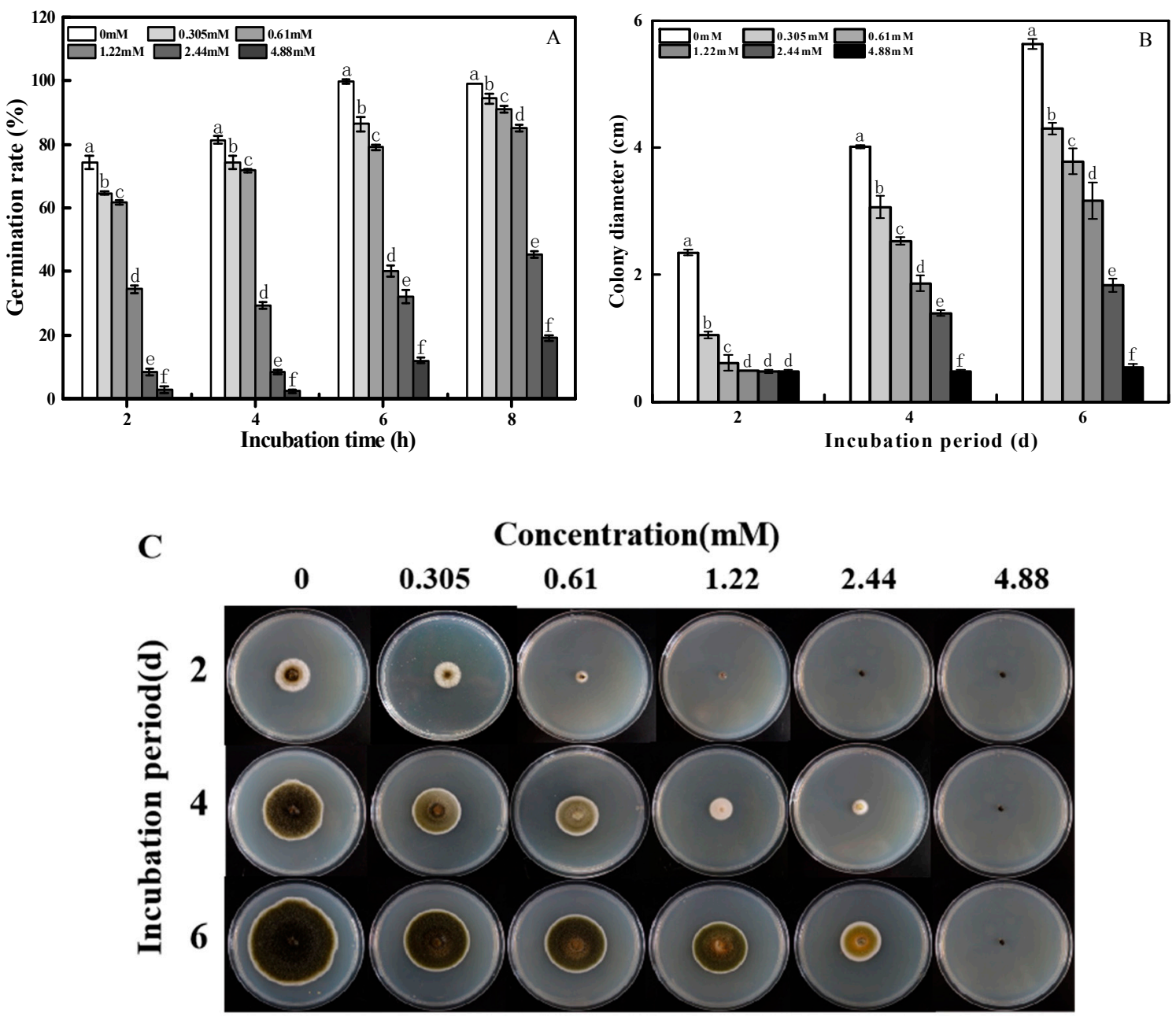

Figure 1. Effects of 2-phenylethyl isothiocyanate on spore germination rates (A), and the mycelial diameter (B) and colony morphology (C) of A. alternata. Colony diameter was examined every 2 days after incubation at $28{ }^{\circ} \mathrm{C}$ for a total of 6 days. Treatments followed by different letters are significantly different according to Duncan's multiple range test $(p<0.05)$.

\subsection{Inhibition of on the Lesion Development of Black Spot in Pear Fruit}

As shown in Figure 2, 2-PEITC treatment significantly controlled black spot caused by A. alternata in pear fruit. The disease severity, indicated by the lesion diameter of black spot, was effectively reduced by 2-PEITC in a dose-dependent manner. The lesion diameter was reduced after 2-PEITC application at a concentration of $0.61 \mathrm{mM}$. At $1.22 \mathrm{mM}$ (MIC), the lesion diameter was only $39 \%$ of that in the control fruit at 7 days after inoculation (Figure 2A,B). However, control effects between MIC and higher concentrations $(2 \times \mathrm{MIC})$ of 2-PEITC fumigation showed no significant difference. 


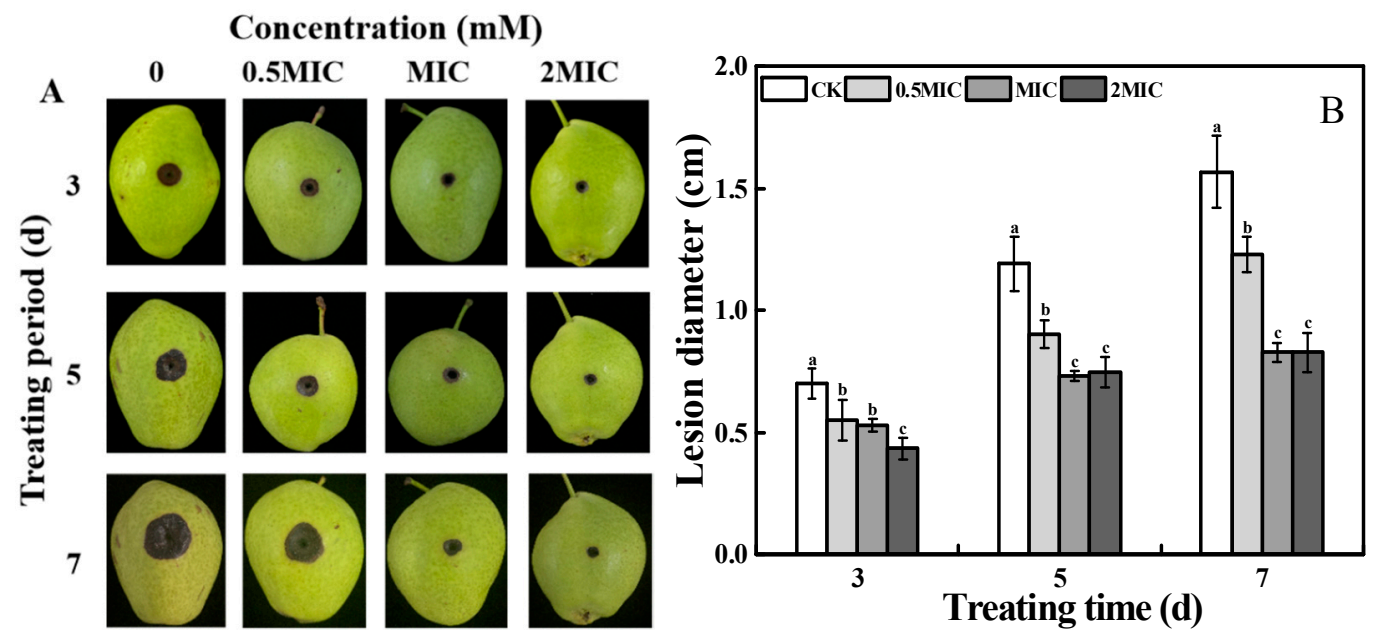

Figure 2. Disease severity of spot disease caused by Alternaria alternata in pear fruits stored at $20 \pm 2{ }^{\circ} \mathrm{C}$ and efficacy of 2-phenylethyl isothiocyanate at various concentrations. (A) Pear fruits at 3, 5, and 7 days of storage. (B) Statistical analysis of lesion diameter shown as histograms. Treatments followed by different letters are significantly different according to Duncan's multiple range test $(p<0.05)$.

\subsection{2-PEITC Damaged Plasma Membrane Integrity of A. alternata}

To further explore the potential antifungal mechanisms of 2-PEITC, propidium iodide (PI), which has the ability to permeate broken cell membrane and emit red fluorescence, was used to test plasma membrane integrity in A. alternata cells. As shown in Figure 3A, mycelia of the control were not stained with PI, and low red fluorescence was observed; however, after 2-PEITC treatment, the fluorescence obviously increased, and 97\% of MIC 2-PEITC-treated cells were stained with PI (Figure 3B).

A

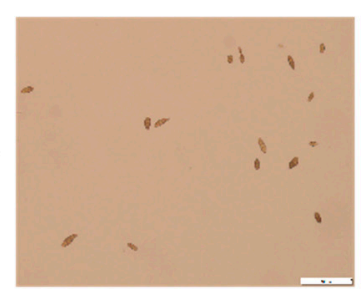

PI

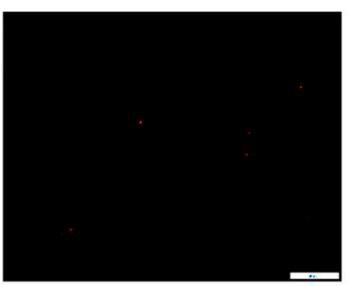

\section{Concentration(mM)}

0.5MIC
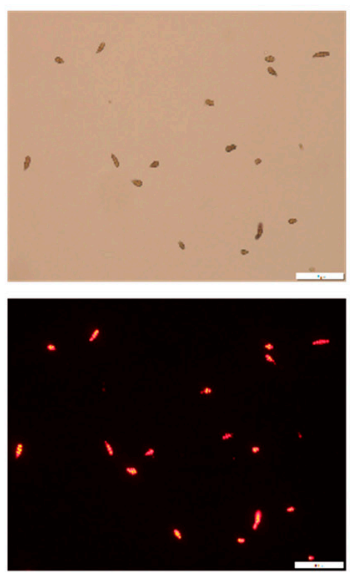

MIC
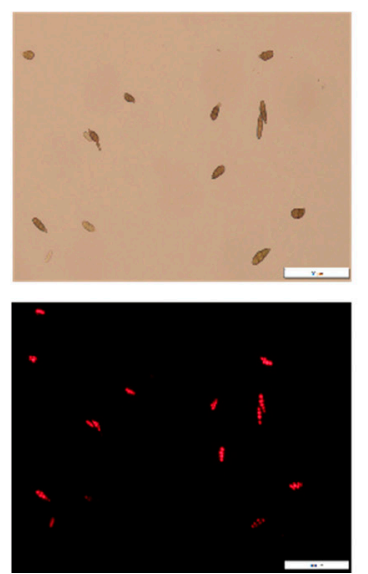

2MIC
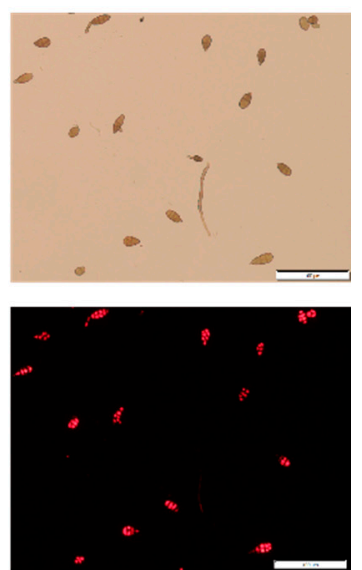

Figure 3. Cont. 


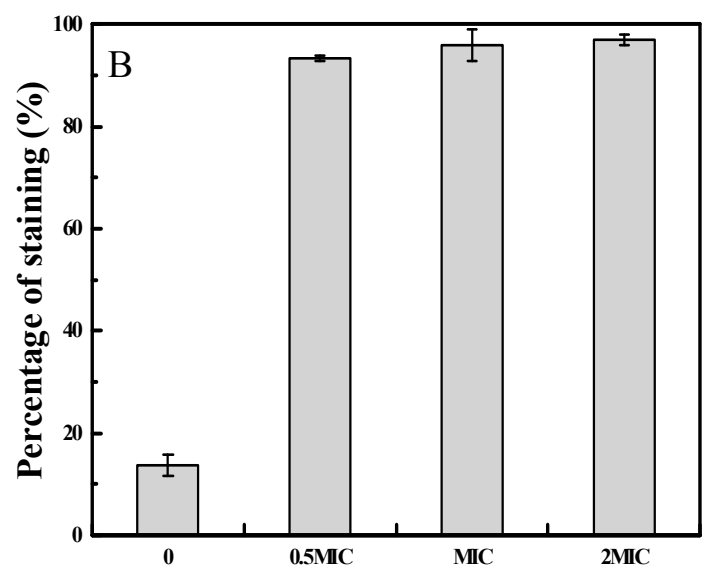

Figure 3. Plasma membrane integrity of A. alternata treated with 2-phenylethyl isothiocyanate at various concentrations. (A) Propidium iodide (PI) staining assay. Scale bars: $100 \mu \mathrm{m}$. (B) percentage of PI staining. Red fluorescence indicates spores with disrupted plasma membranes. Bars represent $100 \mu \mathrm{m}$.

\subsection{Cellular Leakage of A. alternata after 2-PEITC Treatment}

Electrolyte leakage and nucleic acid content were used to determine the permeability of plasma membrane. 2-PEITC treatment clearly increased the electric conductivity of A. alternata. After $120 \mathrm{~min}$ of incubation, electric conductivity of $0.5 \times$ MIC, MIC, and $2 \times$ MIC 2-PEITC-treated A. alternata cells was increased by $10 \%, 33 \%$, and 37\% compared with the control, respectively (Figure $4 \mathrm{~A}$ ). Similarly, leakage occurred after $30 \mathrm{~min}$ of 2-PEITC treatment and nucleic acid content increased after 2-PEITC treatment. After $30 \mathrm{~min}$ treated by 2-PEITC, the $\mathrm{OD}_{260}$ of $A$. alternata was the highest, and the $\mathrm{OD}_{260}$ in the 2-PETIC-treated A. alternata with concentrations of $0.5 \times$ MIC, MIC, and $2 \times$ MIC were 1, 3.08, and 3.37 times higher than the control, respectively (Figure 4B).

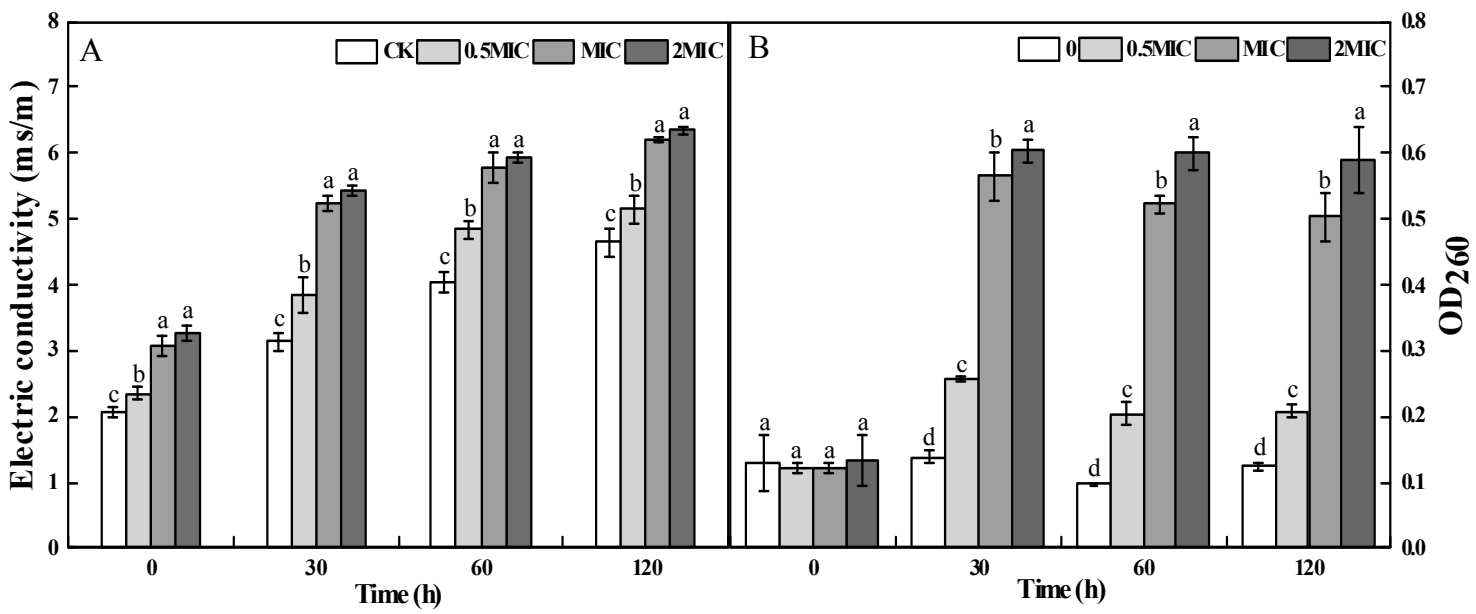

Figure 4. Effect of 2-phenylethyl isothiocyanate on electrolyte leakage (A) and nucleic acid content (B) of A. alternata. Treatments followed by different letters are significantly different according to Duncan's multiple range tests $(p<0.05)$.

\subsection{Production of Mycotoxins by A. alternata upon 2-PEITC Treatment}

Four mycotoxins including tentoxin (TEN), AOH, AME, and ALT were extracted and detected by high performance liquid chromatography-tandem mass spectrometry (HPLC-TOF-ESI-MS) in the mycelium of A. alternata. As shown in Figure 5, the contents of TEN, AOH and AME in A. alternata hypha significantly decreased with the increase of 2-PEITC concentration. The concentrations of TEN, 
$\mathrm{AOH}, \mathrm{AME}$, and ALT in MIC of 2-PEITC-treated groups were only $27 \%, 90 \%, 90 \%$, and $88 \%$ of the corresponding control groups, respectively.

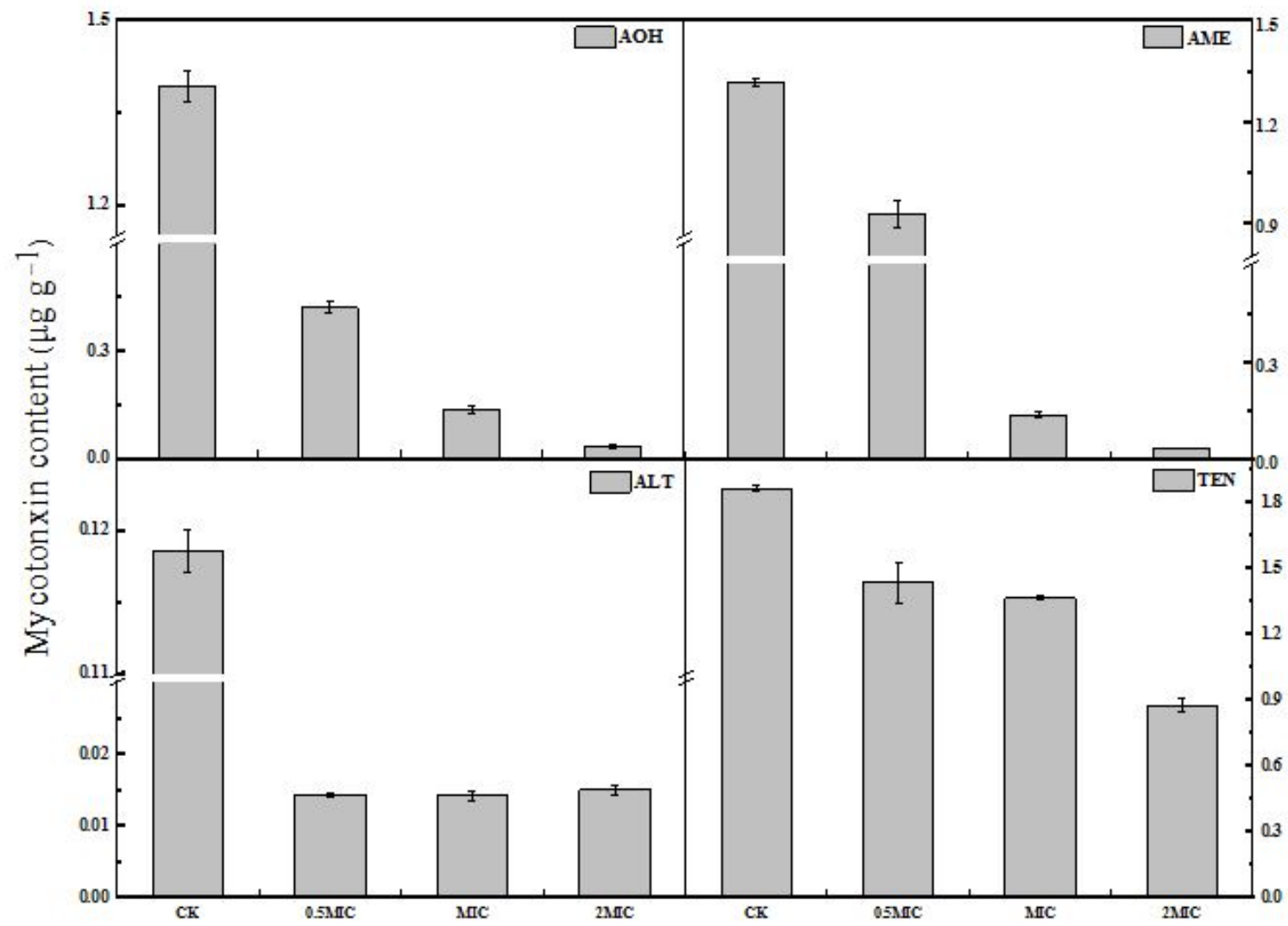

Figure 5. Alternariolmonomethyl ether (AME), alternariol (AOH), altenuene (ALT), and tentoxin (TEN) contents of $A$. alternata treated with 2-phenylethyl isothiocyanate. The amounts of the metabolites were determined by HPLC using triplicate samples and are represented as means \pm standard deviations.

\section{Discussion}

All kinds of plant-derived antifungal compounds such as geraniol, citral, octanal, cinnamaldehyde, and different essential oils, which have potential in targeting fungal pathogens in fresh fruit and vegetables, have been extensively studied [39-42]. Due to the emergence of these natural compounds that bear strong antifungal properties, the use of synthetic fungicides can be reduced. Isothiocyanates, a group of defense-related compounds synthesized by plants of the genus Brassica, are promising alternatives to synthetic chemical fungicides. Evidence has shown that different isothiocyanates possess strong antifungal activity against B. cinerea, Rhizopus stolonifer, M. laxa, Mucor piriformis, and Penicillium expansum [29]. Mari et al. [43] reported that 3-methylsulfinil-3-butenyl-isothiocyanate at a low concentration of $0.02 \mathrm{~g} \mathrm{~L}^{-1}$ inhibited M. laxa, whereas $0.93 \mathrm{~g} \mathrm{~L}^{-1}$ of the same compound was needed to inhibit P. expansum; p-hydroxybenzyl-isothiocyanate inhibited $M$. laxa and P. expansum at $0.09 \mathrm{~g} \mathrm{~L}^{-1}$ concentration; however, $1.8 \mathrm{~g} \mathrm{~L}^{-1}$ was needed to inhibit $R$. stolonifer. In addition, 2-PEITC inhibited mycelial growth of Sclerotinia sclerotiorum in a dose-dependent manner with $100 \%$ inhibition at a concentration of $0.67 \mathrm{mM}$ [15]. Using the same biofumigation method and exposure time, we observed that 2-PEITC at $1.22 \mathrm{mM}$ or higher concentrations entirely inhibited the mycelial growth of $A$. alternata 2 days after treatment (Figure 1), which indicates that the inhibitory effect depends on the type and concentration of the isothiocyanate. Spore germination of A. alternata was also significantly inhibited by 2-PEITC treatment; however, $100 \%$ inhibition was not recorded even at the highest concentration tested (Figure 1A), which indicates that the spore of A. alternata is more resistant to 2-PEITC than 
the mycelium. A similar result reported by Harvey et al. [44] showed $50 \%$ and $90 \%$ inhibition of spore germination in Sclerotium rolfsii by 2-propenyl isothiocyanate at 249 and $528.8 \mathrm{mM}$, respectively. Moreover, AITC exposure in strawberries infected by B. cinerea reduced fruit decay, which indicates that isothiocyanates improve plant defense against microbial pathogens [31]. Results presented in this study showed that 2-PEITC at MIC efficiently decreased black spot disease severity in pear fruit. However, 2-PEITC at $3.06 \mathrm{mM}$ significantly reduced rot of netted melon inoculated with A. alternata [6], which may have been due to the difference in susceptibility of different fruit to 2-PEITC.

Cell membrane is important for the growth and reproduction of microorganisms [45]. The complete cell membrane system is the basis of biophysiological activities. Some studies have suggested that antifungal activity of volatile compounds could be closely correlated with cell membrane integrity of microorganisms [46]. Ji et al. [47] detected loss of membrane integrity in B. cinerea after methyl thujate treatment $\left(60 \mathrm{~g} \mathrm{~L}^{-1}\right)$. Membrane permeability of Penicillium cyclopium increased with increasing concentrations of E-2-hexena, evidenced by cell constituent release and leakage of potassium ions [41]. The current study found the red fluorescence levels in A. alternata cells and fluorescence value in the fungal suspensions visibly increased with 2-PEITC treatment (Figure 3A); the results deduced that 2-PEITC disorganized and disrupted membrane order and integrity. In addition to destroying the plasma membrane, natural compounds could alter transport process in fungi and induce the leakage of intracellular ions $[39,48]$. In the present study, extracellular conductivity increased rapidly after treatment with MIC of 2-PEITC. The maximum extracellular conductivity was examined in A. alternata cell suspension treated with 2-PEITC after $120 \mathrm{~min}$ of incubation (Figure 4A). Meanwhile, a significant increase in nucleic acid leakage was observed after 2-PEITC treatment (Figure 4B). These results further prove that the antifungal activity of isothiocyanates might be due to the disruption of cell membrane integrity in A. alternata.

Mycotoxins are common virulence factors in the host infected by plant pathogens [49]. Alternaria toxins have been shown to exhibit serious effects, and therefore pose a threat to animal and human health. A. alternata is involved in the production of mycotoxins, including AOH, AME, ALT, TEN, and altertoxins (ATX) in fruit and vegetables [50,51]. Some studies have reported that volatile compounds affect the synthesis of toxins. Quiles et al. [32] reported that AITC inhibits the Aspergillus parasiticus growth and aflatoxin (AF) production. However, some studies found that volatile compounds only reduced the amount of mycotoxins. The effects of BITC on Aspergillus ochraceus morphology were related to a decrease in ochratoxin (OT) production, both ochratoxin A (OTA) and ochratoxin $\mathrm{B}$ (OTB) [33]. In the present study, we found that the contents of TEN, AOH, AME, and ALT with the 2-PEITC-treated group significantly decreased compared to the control. This finding agrees with $\mathrm{Xu}$ et al. [52], who reported that $\mathrm{AOH}$ and AME in A. alternata were degraded after cinnamaldehyde treatment $\left(0.200 \mathrm{~mL} \mathrm{~L}^{-1}\right)$ and incubation for $120 \mathrm{~min}$. However, the underlying mechanism 2-PEITC employed to modulate toxin synthesis in A. alternata needs to be further explored.

Although results from the present study and several previous studies showed that isothiocyanates including 2-PEITC derived from plants are biofumigant fungicides against postharvest pathogens such as S. sclerotiorum [15], B. cinerea [31], and P. expansumon [36] through inhibiting vegetative growth, damaging cell membrane, and impairing mycotoxin synthesis, among other factors, most studies only provided experimental evidence. However, isothiocyanates are very low in plant material, and thus a large amount of plant material is needed to isolate sufficient quantities to meet warehouse storage fumigation. In addition, the application of isothiocyanates is limited due to their strong odors, which significantly affect the taste of fruit and vegetables. Thus, some integrated techniques including preparing isothiocyanate mixture [53] and isothiocyanate microcapsules $[11,54,55]$ have been recently explored for their practical application. Meanwhile, the application effect of isothiocyanates depends on the postharvest diseases to be controlled, the application method, the fumigation time, and the type and concentration of isothiocyanates. Therefore, feasible and cost-effective techniques of 2-PEITC application for postharvest disease control need to be further explored. 


\section{Conclusions}

In conclusion, this work elucidated 2-PEITC as an effective antifungal compound to control postharvest black spot disease caused by A. alternata in pear fruit, and the MIC was $1.22 \mathrm{mmol} / \mathrm{L}$ after in vitro experiment. Moreover, 2-PEITC disrupted the permeability and integrity of the fungal membrane that led to leakage of cytoplasmic contents and finally cell death. In addition, 2-PEITC treatment significantly decreased the content of mycotoxins, including TEN, AOH, AME, and ALT, in A. alternata. These results suggest that 2-PEITC could be an alternative fungicide for the control of black spot in pear fruit caused by A. alternata.

\section{Materials and Methods}

\subsection{Fruit and Pathogens}

"Zaosu" pear (Pyrus bretschneideri Rehd) were commercially picked from the Tiaoshan Farm in Jingtai County, Gansu Province, China. Pears of uniform size, with no mechanical damage, no pests, and diseases were selected, and the fruit were individually packaged in a plastic mesh bag, transported the laboratory, and stored at $4{ }^{\circ} \mathrm{C}$. A total of 28 pears were required for this experiment.

The preparation of spore suspension was in reference to Tahir et al. [56]. A total of $10 \mathrm{~mL}$ sterile distilled water containing $0.01 \%(\mathrm{v} / \mathrm{v})$ Tween- 80 was poured into the 7 day A. alternata culture dish under sterile conditions. The spores were scraped with a sterilized applicator and filtered through four layers of sterile cheesecloth and vortexed for $20 \mathrm{~s}$, and the suspension was then adjusted to the required number of spores with a hemocytometer.

\subsection{Mycotoxin Standards and Chemicals}

AOH, AME, ALT, and TEN were purchased from Pribolab (Pte. Ltd. Singapore) and stored at $-20{ }^{\circ} \mathrm{C}$ for HPLC analysis. 2-PEITC was purchased from Shanghai Macklin Biochemical Co., Ltd. (Shanghai, China).

\subsection{In Vitro Inhibitory Effects of 2-PEITC on Growth of A. alternata}

Mycelial growth of A. alternata was measured according to a previously reported method [57]. In short, $2 \mu \mathrm{L}$ spore suspension $\left(1 \times 10^{5} \mathrm{CFU} \mathrm{mL} \mathrm{mL}^{-1}\right)$ was dripped onto the center of each Petri dish mounted with potato dextrose agar (PDA) medium. The amount of 2-PEITC was calculated according to the space of the Petri dish $\left(0.0635 \mathrm{~mm}^{3}\right)$, and a sterilized filter paper disc (20 mm diameter) was attached on the center of the lid inner surface with different concentrations of 2-PEITC $(0.305,0.61$, $1.22,2.44$, and $4.88 \mathrm{mM}$; the unit was defined as 2-PEITC volume per the Petri dish space) added onto the paper, and then the plate was quickly covered. Filter paper without 2-PEITC was used as the control. After the plates were incubated at $28 \pm 1^{\circ} \mathrm{C}$ for 2,4 , and 6 days, the diameter $(\mathrm{cm})$ of the colony area was determined. Each treatment comprised three replicates. The lowest concentration in which no visual hyphal growth was observed after 2 days of incubation was the minimum inhibitory concentration (MIC).

To evaluate the effects of 2-PEITC fumigation on spore germination of A. alternata, the spore suspension $\left(1 \times 10^{5} \mathrm{CFU} \mathrm{mL}{ }^{-1}\right)$ was dripped onto the slide and placed in a large Petri dish with wet filter paper (humidity $=95 \%$ ). The amount of 2-PEITC was calculated according to the space of the Petri dish $\left(0.1905 \mathrm{~mm}^{3}\right)$, and a sterilized filter paper disc $(20 \mathrm{~mm}$ diameter $)$ was attached on the center of the lid inner surface with different concentrations of 2-PEITC $(0.305,0.61,1.22,2.44$, and $4.88 \mathrm{mM}$; the unit was defined as 2-PEITC volume per the Petri dish space) added onto the paper, and then the plate was quickly covered. Treatment without adding 2-PEITC was the control. Spore germination rate was observed and calculated after 2, 4, 6, and $8 \mathrm{~h}$ of incubation. Each treatment comprised three replicates. 


\subsection{Effect of 2-PEITC on A. alternata in Pear Fruit}

The in vivo assay was carried out according to a previously described method with minor modifications [58]. Zaosu pear fruit were dipped into $2 \%$ sodium hypochlorite for $30 \mathrm{~s}$, washed with distilled water and air-dried at room temperature, wounded on the epidermis in the equatorial region with a sterile punch ( $2 \mathrm{~mm}$ deep, $5 \mathrm{~mm}$ wide), and each wound site was inoculated with $20 \mu \mathrm{L}$ of spore suspension at $1 \times 10^{6} \mathrm{CFU} \mathrm{mL} \mathrm{mL}^{-1}$. After $2 \mathrm{~h}$ incubation, the inoculated fruit were fumigated in plastic boxes (lid was drilled with air holes). The amount of 2-PEITC was calculated according to the space of the plastic boxes $(200 \times 130 \times 50 \mathrm{~mm})$, a sterilized filter paper disc ( $30 \mathrm{~mm}$ diameter) was attached on the center of the lid inner surface with different amount of 2 -PEITC $(0.5 \times$ MIC, MIC, $2 \times$ MIC) added onto the paper, and then the plate was quickly covered. Treatment without adding 2-PEITC was the control. Each treatment contained nine fruit. Fruit were fumigated in plastic boxes with humidity $(55 \%)$ at room temperature $\left(23 \pm 1^{\circ} \mathrm{C}\right)$ for 1 day and later taken out and stored in a paper carton (humidity $=55 \%$ ) at room temperature. Disease severity was determined 3, 5, and 7 days after the treatment by measuring the lesion diameter.

\subsection{Determination of Plasma Membrane Integrity}

Membrane integrity of $A$. alternata cells exposed to $0.5 \times \mathrm{MIC}, \mathrm{MIC}$, and $2 \times \mathrm{MIC}$ 2-PEITC was a slightly modified version of a previously described method [59]. Initially, different 2-PEITC concentrations $(0.5 \times \mathrm{MIC}, \mathrm{MIC}, 2 \times \mathrm{MIC})$ were added to the fungal suspension $\left(1 \times 10^{6} \mathrm{CFU} \mathrm{mL}^{-1}\right)$, incubated in a moist chamber at $28 \pm 1^{\circ} \mathrm{C}$ for $30 \mathrm{~min}$, centrifuged at $8000 \mathrm{rpm}$ for $5 \mathrm{~min}$, washed three times with phosphate-buffered saline (PBS, $0.05 \mathrm{M}, \mathrm{pH} 7.2$ ), and stained with propidium iodide (PI) for $5 \mathrm{~min}$ at $30{ }^{\circ} \mathrm{C}$. After centrifugation, fungal suspension was washed three times with PBS solution (0.05 M, pH 7.2) to remove the residual dye, and was observed under a fluorescence microscope (OLYMPUS CORPORATION, Olympus U-LH100HG, Tokyo, Japan) at an excitation wavelength of $620 \mathrm{~nm}$.

\subsection{Detection of Cellular Electrolyte Leakage and Nucleic Acid Content}

Electrolyte leakage of $A$. alternata cells was measured according to a previously described method [60] with minor modifications. 2-PEITC $(0.5 \times \mathrm{MIC}, \mathrm{MIC}, 2 \times \mathrm{MIC})$ was added to the fungal suspension $\left(1 \times 10^{6} \mathrm{CFU} \mathrm{mL}^{-1}\right)$ and incubated for $0,30,60$, and $120 \mathrm{~min}$. Subsequently, the electric conductivity was evaluated in a conductivity meter (DDS-307, Hanghai Yueping Scientific Instrument Co., Ltd. Shanghai, China).

Nucleic acid content of the supernatant was measured following the method of Paul et al. [61] with some modifications. Mycelia of A. alternata culture grown for 4 days in $0.5 \mathrm{~g}$ PDA was collected and resuspended in $15 \mathrm{~mL}$ PBS ( $\mathrm{pH}$ 7.0). The suspension was treated with 2-PEITC at different concentrations $(0.5 \times \mathrm{MIC}, \mathrm{MIC}, 2 \times \mathrm{MIC})$ and incubated at $28 \pm 1^{\circ} \mathrm{C}$ for $0,30,60$, and $120 \mathrm{~min}$. Subsequently, the suspension was centrifuged at 12,000 rpm for $2 \mathrm{~min}$ and the supernatant was collected. Absorbance of the supernatant $(1 \mathrm{~mL})$ was evaluated at $260 \mathrm{~nm}$ with UV-2450 UV/VIS Spectrophotometer (Shimadzu). Each treatment comprised three replicates. The control group was calibrated with PBS ( $\mathrm{pH}=7.0)$.

\subsection{Mycotoxin Extraction and HPLC-MS Analysis}

For mycotoxin extraction, the fungi were cultured in PDA at $28{ }^{\circ} \mathrm{C}$ for 4 days and fumigated with 2-PEITC $(0.5 \times \mathrm{MIC}, \mathrm{MIC}, 2 \times \mathrm{MIC})$, followed by accurately weighed $0.5 \mathrm{~g}$ of $A$. alternata mycelium liquid nitrogen grinding, subsequently the hyphae were transferred to $10 \mathrm{~mL}$ sterile centrifuge tubes, Subsequently, $2.5 \mathrm{~mL}$ of acetonitrile and water extract ( $4: 1 \mathrm{v} / \mathrm{v})$ containing $0.3 \%$ formic acid was added. The solution was vortexed, and was then mixed with $2.5 \mathrm{r} \mathrm{s}^{-1}$ extraction at room temperature for $30 \mathrm{~min}$. Then, $0.25 \mathrm{~g}$ anhydrous $\mathrm{MgSO}_{4}$ and $0.04 \mathrm{~g} \mathrm{NaCl}$ were added, and the mixture was shaken vigorously for $1 \mathrm{~min}$, followed by centrifugation at $180 \mathrm{r} \mathrm{s}^{-1}$ for $10 \mathrm{~min}$ at $4{ }^{\circ} \mathrm{C}$. Finally, the supernatant 
was taken through the 0.22 micron organic filter, quasi-determined to $1.2 \mathrm{~mL}$, and the sample was prepared for HPLC analysis [62].

Separation and qualitative analysis of TEN, AOH, AME, and ALT were performed using a mass spectrometer (Agilent 1290, Anjielun, Shenzhen, China) equipped with the electrospray ionization (ESI) source. HPLC conditions were as a follows: column, C18 $(250 \times 4.6 \mathrm{~mm}, 5 \mu \mathrm{m})$; column temperature, $35^{\circ} \mathrm{C}$; injection volume, $5 \mu \mathrm{L}$; mobile phase A was deionized water, mobile phase B was methanol; gradient elution conditions were A after $70 \%$ retention for $1 \mathrm{~min}$, after falling to $50 \%$ within $2 \mathrm{~min}$, continued to drop to $10 \%$ within $1 \mathrm{~min}$, kept for $2 \mathrm{~min}$, rose to $90 \%$ within $0.1 \mathrm{~min}$, kept for $2 \mathrm{~min}$; tassel $0.005 \mathrm{~mL} \mathrm{~s}^{-1}$; total running time, $7.1 \mathrm{~min}$.

Following the mass spectrometry conditions: ion source mode, positive ion mode $\left(\mathrm{ESI}^{+}\right)$; mass spectrometry scanning mode, multiple reaction monitoring (MRM); sheath gas temperature, $350{ }^{\circ} \mathrm{C}$; nebulizer pressure, $35 \mathrm{psi}$; sheath gas flow, $0.183 \mathrm{~L} \mathrm{~s}^{-1}$; capillary voltage, $4000 \mathrm{~V}$; other parameters were adjusted to optimum by the instrument. The mass spectrometric parameters such as monitoring ion, cone voltage, and collision voltage of four Alternaria species are shown in Table 1.

Table 1. Optimized multiple reaction monitoring (MRM) parameters for AOH, AME, ALT, and TEN mycotoxins.

\begin{tabular}{|c|c|c|c|c|c|c|c|}
\hline Target Compounds & $\begin{array}{c}\text { Ionization } \\
\text { Mode }\end{array}$ & Parent Ion & $\begin{array}{l}\text { Qualitative } \\
\text { Ion }\end{array}$ & $\begin{array}{l}\text { Keep } \\
\text { Time }\end{array}$ & $\begin{array}{c}\text { Quantitative } \\
\text { Ion }\end{array}$ & $\begin{array}{c}\text { Fragmentation } \\
\text { Voltage }\end{array}$ & $\begin{array}{c}\text { Collision } \\
\text { Voltage }\end{array}$ \\
\hline Altemariol (AOH) & $\mathrm{ESI}^{+}$ & 257.0 & 213.0 & 2.37 & 147.2 & 40 & 32 \\
\hline $\begin{array}{c}\text { Altermariol } \\
\text { monomethylether (AME) }\end{array}$ & $\mathrm{ESI}^{+}$ & 271.0 & 256.0 & 2.85 & $\begin{array}{l}228.0 \\
212.9\end{array}$ & 32 & 20 \\
\hline Allenuene (ALT) & $\mathrm{ESI}^{+}$ & 293.1 & 257.2 & 3.33 & 239.1 & 85 & 15 \\
\hline Tentoxin (TEN) & $\mathrm{ESI}^{+}$ & 415.2 & 312.3 & 3.66 & 189.0 & 110 & 30 \\
\hline
\end{tabular}

\subsection{Statistical Analysis}

All data were expressed as mean \pm SD by measuring three independent parallel replicates. The significance of the mean difference between the treatments at the $5 \%$ level was calculated by Duncan's test using SPSS (version 13.0, SPSS Inc., Chicago, IL, USA).

Author Contributions: Conceived and designed the experiments, M.Z., Y.B., and Y.L.; performed the experiments, M.Z., T.W., T.Z., Q.Y., and Y.D.; analyzed the data and wrote the paper, M.Z. All authors reviewed the manuscript and agreed to the published version of the manuscript.

Funding: This work was supported by the National Key Research and Development Program of China (2018YFD0401302).

Acknowledgments: We thank members of Chinese Academy of Inspection and Quarantine for mycotoxin analysis.

Conflicts of Interest: The authors declare no conflict of interest.

\section{References}

1. Vilaplana, R.; Páez, D.; Valencia-Chamorro, S. Control of black rot caused by Alternaria alternata in yellow pitahaya (Selenicereus megalanthus) through hot water dips. LWT Food Sci. Technol. 2017, 82, 162-169. [CrossRef]

2. Yang, J.; Sun, C.; Zhang, Y.; Fu, D.; Zheng, X.; Yu, T. Induced resistance in tomato fruit by $\gamma$-aminobutyric acid for the control of Alternaria rot caused by Alternaria Alternata. Food Chem. 2017, 221, 1014-1020. [CrossRef] [PubMed]

3. Estiarte, N.; Crespo-Sempere, A.; Marín, S.; Sanchis, V.; Ramos, A.J. Exploring polyamine metabolismo of Alternaria alternata to target new substances to control the fungal infection. Food Microbiol. 2017, 65, 193-204. [CrossRef] [PubMed]

4. Gabriel, M.F.; Uriel, N.; Teifoori, F.; Postigo, I.; Suñén, E.; Martínez, J. The major Alternaria alternata allergen, Alta1: A reliable and specific marker of fungal contamination in citrus fruit. Int. J. Food Microbiol. 2017, 257, 26-30. [CrossRef] [PubMed] 
5. Castro, J.C.; Endo, E.H.; Souza, M.R.; Zanqueta, E.B.; Polonio, J.C.; Pamphile, J.A.; UedaNakamura, T.; Nakamura, C.V.; Dias Filho, B.P.; Abreu Filho, B.A. Bioactivity of essential oils in the control of Alternaria alternata in dragon fruit (Hylocereusundatus Haw.). Ind. Crop. Prod. 2017, 97, 101-109. [CrossRef]

6. Troncoso-Rojas, R.; Corral-Acosta, Y.; Alberto, S.; Raymundo, G.; Aguilar-Valenzuela, A.; Ojeda-Contreras, J. Postharvest treatment of isothiocyanates to control alternaria rot in netted melon. Phytoparasitica 2009, 37, 445-451. [CrossRef]

7. Li, Y.C.; Bi, Y.; An, L.Z. Occurrence and latent infection of Alternaria rot of Pingguoli pear (Pyrusbretschneideri Rehd. cv. Pingguoli) fruit in Gansu, China. J. Phytopathol. 2007, 155, 56-60. [CrossRef]

8. Estiarte, N.; Crespo-Sempere, A.; Marín, S.; Sanchis, V.; Ramos, A.J. Effect of 1-methylcypropopene on the development of black mold disease and its potential effect on alternariol and alternariolmonomethyl ether biosynthesis on tomatoes infected with Alternaria alternata. Int. J. Food Microbiol. 2016, 236, 74-82. [CrossRef]

9. Andersen, B.; Nielsen, K.F.; Pinto, V.F.; Patriarca, A. Characterization of Alternaria strains from Argentinean blueberry, tomato, walnut and wheat. Int. J. Food Microbiol. 2015, 196, 1-10. [CrossRef]

10. Braghini, R.; Sucupira, M.; Rocha, L.O.; Reis, T.A.; Aquino, S.; Corrêa, B. Effects of gamma radiation on the growth of Alternaria alternata and on the production of alternariol and alternariolmonomethyl ether in sunflower seeds. Food Microbiol. 2009, 26, 927-931. [CrossRef]

11. Piercey, M.J.; Mazzanti, G.; Budge, S.M.; Delaquis, P.J.; Paulson, A.T.; Hansen, L.T. Antimicrobial activity of cyclodextrin entrapped allyl isothiocyanate in a model system and packaged fresh-cut onions. Food Micobiol. 2012, 30, 213-218. [CrossRef] [PubMed]

12. Elad, Y.; Pertot, I.; Cores-Prado, A.M.; Stewart, A. Plant hosts of Botrytis spp. In Botrytis—The Fungus, the Pathogen and Its Management in Agricultural Systems; Fillinger, S., Elad, Y., Eds.; Springer: Berlin, Germany, 2016; pp. 413-486.

13. Soylu, E.M.; Kose, F. Antifungal activities of essential oils against citrus black rot disease agent Alternaria alternata. J. Essent. Oil Bear. Plants 2015, 18, 894-903. [CrossRef]

14. Tian, S.P.; Torres, R.; Ballester, A.R.; Li, B.Q.; Vilanova, L.; González-Candelas, L. Molecular aspects in pathogen-fruit interactions: Virulence and resistance. Postharvest Biol. Technol. 2016, 122, 11-21. [CrossRef]

15. Kurt, S.; Güneş, U.; Soylu, E.M. In vitro and in vivo antifungal activity of synthetic pure isothiocyanates against Sclerotinia sclerotiorum. Pest Manag. Sci. 2011, 67, 869-875. [CrossRef]

16. Motisi, N.; Montfort, F.; Romillac, N.; Lucas, P. Duration of control of two soilborne pathogens following incorporation of above and below-ground residues of brassica juncea into soil. Plant Pathol. 2010, 58, 470-478. [CrossRef]

17. Fahey, J.W.; Zalcmann, A.T.; Talalay, P. The chemical diversity and distribution of glucosinolates and isothiocyanates among plants. Phytochemistry 2001, 56, 5-51. [CrossRef]

18. Gaurav, K.; Hardeep, S.T.; Sonam, M.; Jitendra, K.S.; Anil, T.; Sardul, S.S. Isothiocyanates: A class of bioactive metabolites with chemopreventive potential. Tumor Biol. 2015, 36, 4005-4016.

19. Besma, A.; Lucas, C.R.; Riedl, K.M.; Clinton, S.K.; Amir, M. Cruciferous vegetables, isothiocyanates and bladder cancer prevention. Mol. Nutr. Food Res. 2018, 1, 272-282.

20. Melina, M.; Tom, A.; Rodrigo, F.; Vasilis, Z.; Aglaia, P.; Panayiotidis, M.I. From chemo-prevention to epigenetic regulation: The role of isothiocyanates in skin cancer prevention. Pharmacol. Ther. 2018, 190, 187-201.

21. Kris-Etherton, P.M.; Hecker, K.D.; Bonanome, A.; Coval, S.M.; Binkoski, A.E.; Hilpert, K.F.; Griel, A.E.; Etherton, T.D. Bioactive compounds in foods: Their role in the prevention of cardiovascular disease and cancer. Am. J. Med. 2002, 113, 71-88. [CrossRef]

22. Dhingra, O.D.; Costa, M.L.N.; Silva, G.J. Potential of allylisothiocyanate to control Rhizoctoniasolani seedling damping off and seedling blight in transplant production. J. Phytopathol. 2004, 152, 352-357. [CrossRef]

23. Zasada, I.A.; Ferris, H. Sensitivity of Meloidogynejavanica and Tylenchulussemipenetrans to isothiocyanates in laboratory assays. Phytopathology 2003, 93, 747-750. [CrossRef]

24. Buskov, S.; Serra, B.; Rosa, E.; Sorensen, H.; Sorensen, J.C. Effects of intact glucosinolates and products produced from glucosinolates in myrosinase-catalyzed hydrolysis on the potato cyst nematode (GloboderarostochiensiscvWoll). J. Agric. Food Chem. 2002, 50, 690-695. [CrossRef]

25. Haristoy, X.; Fahey, J.W.; Scholtus, I.; Lozniewski, A. Evaluation of the antimicrobial effects of several isothiocyanates on Helicobacter pylori. Planta Med. 2005, 71, 326-330. [CrossRef]

26. Nadarajah, D.; Han, J.H.; Holley, R.A. Use of mustard flour to inactivate Escherichia coli O157:H7 in ground beef under nitrogen flushed packaging. Int. J. Food Mocrobiol. 2005, 99, 257-267. [CrossRef] 
27. Agrawal, A.A.; Kurashige, N.S. A role for isothiocyanates in plant resistance against the specialist Herbivore Pierisrapae. J. Chem. Ecol. 2003, 29, 1403-1415. [CrossRef]

28. Peterse, J.; Belz, R.; Waker, F.; Hurle, K. Weed suppression by release of isothiocyanates from turnip-rape mulch. Agron. J. 2001, 93, 37-43. [CrossRef]

29. Tiznado-Hernández, M.; Troncoso-Rojas, R. Control of fungal diseases with isothiocyanates. Stewart Postharvest Rev. 2006, 2, 1-14.

30. Mari, M.; Leoni, O.; Bernardi, R.; Neri, F.; Palmieri, S. Control of brown rot on stonefruit by synthetic and glucosinolate-derived isothiocyanates. Postharvest Biol. Technol. 2008, 47, 61-67. [CrossRef]

31. Ugolini, L.; Martini, C.; Lazzeri, L.; Lorenzo, D.; Mari, M. Control of postharvest grey mould (Botrytis cinerea per.: Fr.) on strawberries by glucosinolate-derived allyl-isothiocyanate treatments. Postharvest Biol. Technol. 2014, 90, 34-39. [CrossRef]

32. Quiles, J.M.; Manyes, L.; Luciano, F.; Manes, J.; Meca, G. Influence of the antimicrobial compound allylisothiocyanate against the Aspergillus parasiticus growth and its aflatoxins production in pizza crust. Food Chem. Toxicol. 2015, 83, 222-228. [CrossRef]

33. Clemente, I.; Aznar, M.; Nerín, C. Effect of an active label based on benzyl isothiocyanate on the morphology and ochratoxins production of, Aspergillus ochraceus. Food Res. Int. 2017, 101, 61-72. [CrossRef]

34. Hu, P.; Wang, A.S.; Engledow, A.S.; Hollister, E.B.; Rothlisberger, K.L.; Matocha, J.E. Inhibition of the germination and growth of Phymatotrichopsis omnivora (cotton root rot) by oilseed meals and isothiocyanates. Appl. Soil Ecol. 2011, 49, 68-75. [CrossRef]

35. Troncoso-Rojas, R.; Sanchez-Estrada, A.; Ruelas, C.; Garcia, H.S.; Tiznado-Hernandez, M.E. Effect of benzyl isothiocyanate on tomato fruit infection development by Alternaria Alternata. J. Sci. Food Agric. 2005, 85, 1427-1434. [CrossRef]

36. Mari, M.; Leoni, O.; Iori, R.; Cembali, T. Antifungal vapour-phase activity of allyl-isothiocyanate against Penicillium expansum on pears. Plant Pathol. 2002, 51, 231-236. [CrossRef]

37. Smith, B.J.; Kirkegaard, J.A. In-vitro inhibition of soil microorganisms by 2-phenylethyl isothiocyanate. Plant Pathol. 2002, 51, 585-593. [CrossRef]

38. Aires, A.; Mota, V.R.; Saavedra, M.J.; Rosa, E.A.S.; Bennett, R.N. The antimicrobial effects of glucosinolates and their respective enzymatic hydrolysis products on bacteria isolated from the human intestinal tract. J. Appl. Microbiol. 2009, 106, 2086-2095. [CrossRef]

39. Tao, N.G.; Ouyang, Q.; Jia, L. Citral inhibits mycelial growth of penicillium italicum by a membrane damage mechanism. Food Control 2014, 382, 116-121. [CrossRef]

40. Linde, J.H.; Combrinck, S.; Regnier, T.J.C.; Virijevic, S. Chemical composition and antifungal activity of the essential oils of Lippiarehmannii from South Africa. S. Afr. J. Bot. 2010, 76, 37-42. [CrossRef]

41. Zhang, J.; Tian, H.; Sun, H. Antifungal activity of trans-2-hexenal against Penicillium cyclopium by a membrane damage mechanism. J. Food Biochem. 2017, 41, e12289. [CrossRef]

42. Yun, D.G.; Lee, D.G. Silymarin exerts antifungal effects via membrane-targeted mode of action by increasing permeability and inducing oxidative stress. BBA Biomembr. 2017, 1859, 467-474. [CrossRef] [PubMed]

43. Mari, M.; Iori, R.; Leoni, O.; Marchi, A. In vitro activity of glucosinolate-derived isothiocyanates against post-harvest fruit pathogens. Ann. Appl. Biol. 1993, 123, 155-164. [CrossRef]

44. Harvey, S.G.; Hannahan, H.N.; Sams, C.E. Indian mustard and allylisothiocyanate inhibit Sclerotium rolfsii. J. Am. Soc. Hortic. Sci. 2002, 127, 27-31. [CrossRef]

45. Huang, Y.; Sekhon, N.S.; Borninski, J.; Chen, N.; Rubinsky, B. Instantaneous, quantitative single-cell viability assessment by electrical evaluation of cell membrane integrity with microfabricated devices. Sens. Actuators A Phys. 2003, 105, 31-39. [CrossRef]

46. Zhou, H.; Tao, N.G.; Jia, L. Antifungal activity of citral, octanal and $\alpha$-terpineol against Geotrichumcitri-aurantii. Food Control 2014, 37, 277-283. [CrossRef]

47. Ji, D.; Chen, T.; Ma, D.; Liu, J.; Xu, Y.; Tian, S. Inhibitory effects of methyl thujate on mycelial growth of, Botrytis cinerea, and possible mechanisms. Postharvest Biol. Technol. 2018, 142, 46-54. [CrossRef]

48. Helal, G.A.; Sarhan, M.M.; Abu Shahla, A.N.K.; Abou El-Khair, E.K. Effects of Cymbopogoncitratus L. essential oil on the growth: Morphogenesis and aflatoxin production of Aspergillus flavus ML2-strain. J. Basic Microbiol. 2007, 47, 5-15. [CrossRef]

49. Howlett, B.J. Secondary metabolite toxins and nutrition of plant pathogenic fungi. Curr. Opin. Plant Biol. 2006, 9, 371-375. [CrossRef] 
50. Troncoso-Rojas, R.; Tiznado-Hernández, M.E. Alternaria alternata (Block rot, black spot). In Postharvest Decay; Bautista-Banos, S., Ed.; Academic Press: Cambridge, MA, USA, 2014; pp. 147-187.

51. López, P.; Venema, D.; de Rijk, T.; de Kok, A.; Sholten, J.M.; Mol, H.G.J.; de Nijs, M. Occurrence of Alternaria toxins in food products in the Netherlands. Food Control 2016, 60, 196-204. [CrossRef]

52. Xu, L.; Tao, N.G.; Yang, W. Cinnamaldehyde damaged the cell membrane of, Alternaria alternata, and induced the degradation of mycotoxins, in vivo. Ind. Crop. Prod. 2018, 112, 427-433. [CrossRef]

53. Wu, H.; Zhang, X.; Zhang, G.A.; Zeng, S.Y.; Lin, K.C. Antifungal vapour, hase activity of a combination of allyl isothiocyanate and ethyl isothiocyanate against botrytis cinerea and penicillium expansum infection on apples. J. Phytopathol. 2011, 159, 450-455.

54. Li, X.; Jin, Z.; Wang, J. Complexation of allyl isothiocyanate by a- and b-cyclodextrin and its controlled release characteristics. Food Chem. 2007, 103, 461-466. [CrossRef]

55. Wu, H.; Xue, N.; Hou, C.; Feng, J.; Zhang, X. Microcapsule preparation of allyl isothiocyanate and its application on mature green tomato preservation. Food Chem. 2015, 175, 344-349. [CrossRef] [PubMed]

56. Tahir, I.I.; Nybom, H.; Ahmadi-Afzadi, M.; Røen, K.; Sehic, J.; Røen, D. Susceptibility to blue mold caused by Penicillium expansum in apple cultivars adapted to a cool climate. Eur. J. Hortic. Sci. 2015, 80, 117-127. [CrossRef]

57. Jiang, Y.; Wang, D.; Li, F.; Li, D.P.; Huang, Q.R. Cinnamon essential oil Pickering emulsion stabilized by zein-pectincomposite nanoparticles: Characterization, antimicrobial effect andadvantages in storage application. Int. J. Biol. Macromol. 2019. [CrossRef]

58. Li, H.; Zhang, Z.Q.; He, C.; Qin, G.Z.; Tian, S.P. Comparative proteomics reveals the potential targets of BcNoxR, a putative regulatory subunit of NADPH oxidase of Botrytis cinerea. Mol. Plant Microbe. Interact. 2016, 29, 990-1003. [CrossRef]

59. Liu, J.; Zong, Y.Y.; Qin, G.Z.; Li, B.Q.; Tian, S.P. Plasma membrane damage contributes to antifungal activity of silicon against Penicillium digitatum. Curr. Microbiol. 2010, 61, 274-279. [CrossRef]

60. Shao, X.; Cheng, S.; Wang, H.; Yu, D.; Mungai, C. The possible mechanism of antifungal action of tea tree oil on Botrytis cinerea. J. Appl. Microbiol. 2013, 114, 1642-1649. [CrossRef]

61. Paul, S.; Dubey, R.C.; Maheswari, D.K.; Kang, S.C. Trachyspermumammi (L.) fruit essential oil influencing on membrane permeability and surface characteristics in inhibiting food-borne pathogens. Food Control 2001, 22, 725-731. [CrossRef]

62. Wang, M.; Jiang, N.; Xian, H.; Wei, D.; Shi, L.; Feng, X. A single-step solid phaseextraction for the simultaneous determination of 8 mycotoxins in fruit by ultra-highperformance liquid chromatography tandem mass spectrometry. J. Chromatogr. A 2016, 1429, 22-29. [CrossRef] 